Volume 112, Number 5

Table I. Plasma nitrite plus nitrate concentrations ( $\mu \mathrm{mol} / L$ ) in patients undergoing CPB

\begin{tabular}{ccccc}
\hline Time point & $37^{\circ} \mathrm{C}$ with pulsatile flow & $37^{\circ} \mathrm{C}$ with nonpulsatile flow & $28^{\circ} \mathrm{C}$ with pulsatile flow & $28^{\circ} \mathrm{C}$ with nonpulsatile flow \\
\hline A & $30.3 \pm 12.4$ & $41.3 \pm 4.8$ & $37.8 \pm 13.8$ & $47.2 \pm 8.9$ \\
B & $33.8 \pm 14.8$ & $39.6 \pm 12.6$ & $27.4 \pm 6.1$ & $52.6 \pm 7.6$ \\
C & $38.6 \pm 15.5$ & $35.3 \pm 7.4$ & $32.7 \pm 13.1$ & $45.7 \pm 13.3$ \\
D & $30.9 \pm 12.1$ & $36.6 \pm 8.5$ & $22.7 \pm 8.7$ & $66.5 \pm 11.3^{*}$ \\
E & $34.0 \pm 10.2$ & $23.1 \pm 3.3^{* \dagger}$ & $26.7 \pm 10.0$ & $51.0 \pm 10.9$ \\
F & $35.1 \pm 13.7$ & $30.6 \pm 9.1$ & $34.2 \pm 14.9$ & $51.8 \pm 12.4$
\end{tabular}

Timepoints defined in text. Values presented as mean \pm standard error of the mean.

${ }^{*}$ Significant difference from isothermic pulsatile flow group at same time point $(p<0.05)$.

$\uparrow$ Significant difference from time point $\mathrm{A}$ in same group $(p<0.05)$.

sion at $37^{\circ} \mathrm{C}^{5}$ The cause of the elevated plasma nitrite plus nitrate levels in this group is unlikely to have been simply the release of stored metabolites built up during aortic crossclamping because the same effect was not observed in the other three groups, in which an identical manouver was performed. Our results clearly indicate the need for further studies designed to examine in greater detail the regional hemodynamic effects of NO associated with pulsatile perfusion and hypothermia.

\section{REFERENCES}

1. Taylor KM, Casals JG, Mittra SM, Brannan JJ, Morton IJ. Haemodynamic effects of angiotensin converting enzyme inhibition after cardiopulmonary bypass in dogs. Cardiovasc Res 1980;14:199-205.
2. Levine FH, Philbin DM, Kono K, Coggins CH, Emerson CW, Austen WG, et al. Plasma vasopressin levels and urinary sodium excretion during cardiopulmonary bypass with and without pulsatile flow. Ann Thorac Surg 1981;32:63-7.

3. Pohl U, Busse R, Kuon E, Bassenge E. Pulsatile perfusion stimulates the release of endothelial autacoids. J Appl Cardiol 1986;1:215-35.

4. Hutcheson IR, Griffith TM. Release of endothelium-derived relaxing factor is modulated both by frequency and amplitude of pulsatile flow. Am J Physiol 1991;261(1 Pt 2):H257-62.

5. Taylor KM. Pulsatile and non-pulsatile perfusion. In: Minami K, Körfer R, Wada J, editors. Cardio-thoracic surgery: what's new in current practice. Amsterdam: Excerpta Medica, 1992: $57-65$.

\title{
VIDEO-ASSISTED THORACOSCOPIC LOCAL EXCISION OF PULMONARY ARTERIOVENOUS FISTULA
}

Masato Minami, MD, Yoshitaka Fujii, MD, Takatoshi Mizuta, MD, Hiroki Kishima, MD, and Hikaru Matsuda, MD, Osaka, Japan

Recent advances in therapeutic embolization have made nonsurgical treatment of pulmonary arteriovenous malformation preferred over conventional surgical excision., ${ }^{1,2}$ In embolization therapy there is a possibility of incomplete treatment and a risk of accidental systemic embolization, ${ }^{3}$ however, so surgical excision is considered appropriate for at least some patients. In such cases, conservative operation, such as wedge resection and local excision, is desirable if possible. In this report, video-assisted thoracoscopic surgical

From the First Department of Surgery, Osaka University Medical School, Suita, Osaka, Japan.

Received for publication April 8, 1996; accepted for publication April 17, 1996.

J Thorac Cardiovase Surg 1996;112:1395-7

Copyright (C) 1996 by Mosby-Year Book, Inc.

$0022-5223 / 96 \$ 5.00+0 \quad \mathbf{1 2 / 5 4 / 7 4 1 7 8}$ technique, which has recently been applied to a variety of thoracic lesions, was adopted as a less invasive modality to excise a pulmonary arteriovenous fistula (PAVF).

A 35-year-old man was referred for a nodule in the right middle field that was found on a chest roentgenogram. He had no symptoms but had a continuous murmur on the right side of the anterior chest. A computed tomogram showed a $2 \mathrm{~cm}$ PAVF just beneath the visceral pleura in subsegment $3 \mathrm{~b}$ of the right upper lobe, which was fed from the dilated A. lobi sup. vent. medialis and drained to V. ventralis superior. There were no other lesions. Pulmonary arteriography revealed a noncavernous, well-demarcated PAVF with single feeder and drainage vessels (Fig. 1). Blood hemoglobin content was $16.4 \mathrm{gm} / \mathrm{dl}$. Arterial blood gas analysis showed an arterial oxygen tension of 84 $\mathrm{mm} \mathrm{Hg}$, an arterial carbon dioxide tension of $38 \mathrm{~mm} \mathrm{Hg}$, and an arterial oxygen saturation of $95 \%$. Shunt fraction was estimated at $19 \%$. 


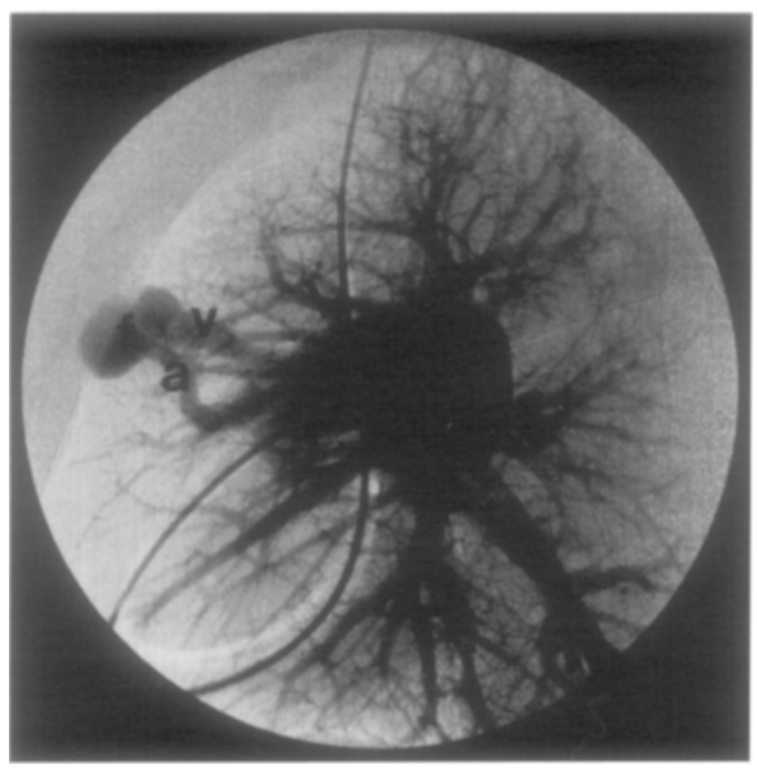

Fig. 1. Preoperative pulmonary arteriogram in deep left anterior oblique view shows noncavernous, well-demarcated PAVF $(f)$ with single feeding artery $(a)$ and drainage vein (v) just beneath visceral pleura.

On December 26, 1994, the patient underwent surgical excision under general anesthesia and with single-lung ventilation. A $10 \mathrm{~mm}$, 0-degree rigid telescope (GN26033AP; Karl Storz, GMBH \& Co., Tuttlingen, Germany) was introduced through a port made in the eighth intercostal space on the posterior axillary line in the left decubitus position. Two additional ports were made in the seventh intercostal space on the anterior axillary line and sixth intercostal space on the posterior axillary line to introduce a $10 \mathrm{~mm}$ diameter endosurgical ultrasonographic probe (UST-5522-7.5; Aloka Co., Ltd., Tokyo, Japan) and to manipulate the lung, respectively. Furthermore, a $6 \mathrm{~cm}$ long utility thoracotomy was performed without rib spreading along the fifth intercostal space from midaxillary to anterior axillary line to introduce aortic clamp forceps and to prepare for any accidental bleeding. The ultrasonographic probe was operated at 7.5 $\mathrm{MHz}$ with a portable ultrasonographic unit (SSD-1200; Aloka) set up to view ultrasonographic and videothoracoscopic images simultaneously.

A dark blue 2 to $3 \mathrm{~cm}$ pulsatile lesion that protruded from the lung was easily visible on the anterolateral surface of the right upper lobe. Intraoperative intrathoracic ultrasonography showed a clearly smooth-surfaced cystic lesion connected to a pair of distinct echogeneic tubular architectures, which were judged to be the feeder and drainage vessels (Fig. 2). Saline solution poured into the pleural cavity improved surface contact of the transducer and resulted in better resolution. With en bloc clamping of the circumferential lung tissue by forceps used to occlude the blood flow of the PAVF, the pleura was incised with electrocautery all around the lesion. The



Fig. 2. Intraoperative intrathoracic ultrasonogram. $\operatorname{PAVF}(f)$, feeding artery $(a)$, and drainage vein $(v)$ are clearly defined. Left side is the cranial side.

wall of the PAVF was bluntly and sharply exposed from the surrounded parenchyma by a cotton-tipped dissector and electrocautery until both the feeding and drainage vessels were exposed. The fistula was excised after these vessels were doubly ligated. The pleura was sutured over and over, and the clamp was released with neither hemorrhage nor air leakage. The chest was closed and a drainage tube was left in place.

The postoperative course was uncomplicated, and the chest drain was extubated on the second postoperative day. The patient was able to leave the hospital on the fourth postoperative day. Three months after the operation, a pulmonary arteriogram showed no residual PAVF in the area operated on. A small, previously unidentified PAVF was found in the left lower lobe, however, and the patient is now being closely followed up.

It is usually not difficult to locate a PAVF through an open thoracotomy, if it is close below the visceral pleura, by finding a protrusion from the pleural surface and palpating a thrill. In the thoracoscopic approach, however, digital examination is not always easy to apply. In this case, ultrasonographic guidance proved useful not only in detection of the lesion but in evaluation of its size, shape, and above all relationship with vessels for appropriate positioning of the clamp. In fact, it was possible to occlude blood flow of the PAVF exactly, expose the fistula safely, and ligate both the artery and vein independently. The 
merit of intraoperative intrathoracic ultrasonography, which has been reported for localization of lung tumors, ${ }^{4}$ may be greater for vascular lesions. Color Doppler ultrasonography would be more informative, although we could not use it.

Although in this case we did not use an endosurgical stapler for fear of sudden massive bleeding in case of incomplete stapling or tear of the pleura along the staple line, the lesion may have been resectable by stapling. Also, permanent occliusion of the blood flow of a PAVF by an endosurgical stapler without a knife may be possible if the lesion is small enough. Three ports and utility thoracotomy taken together are not much smaller than a conventional axillary thoracotomy, but we considered it important to avoid rib spreading. Furthermore, with more experience, we could use an endosurgical clamp to occlude the pulmonary blood flow without utility thoracotomy. In our case, at least, all the goals of the conventional approach of surgical excision of PAVF by thoracotomy were accomplished with the video-assisted thoracoscopic surgical approach. Because PAVFs are usually close to the visceral pleura, ${ }^{5}$ video-assisted thoracoscopic surgical intervention may become the treatment of choice.

\section{REFERENCES}

1. Hartnell GG, Allison DJ. Coil embolization in the treatment of pulmonary arteriovenous malformations. J Thorac Imaging $1989 ; 4: 81-5$.

2. White RI Jr, Lynch-Nyhan A, Terry P, Buescher PC, Farmlett EJ, Charnas L, et al. Pulmonary arteriovenous malformations: techniques and long-term outcome of embolotherapy. Radiology 1988;169:663-9.

3. Puskas JD, Allen MS, Moncure AC, Wain JC Jr, Hilgenberg $\mathrm{AD}$, Wright $\mathrm{C}$, et al. Pulmonary arteriovenous malformations: therapeutic options. Ann Thorac Surg 1993;56:253-7.

4. Shennib H, Bret P. Intraoperative transthoracic ultrasonographic localization of occult lung lesions. Ann Thorac Surg 1993;55:767-9.

5. Burke CM, Safai C, Nelson DP, Raffin TA. Pulmonary arteriovenous malformations: a critical update. Am Rev Respir Dis 1986;134:334-9.

\section{BRONCHIAL NECROSIS INDUCED BY INHALATION OF AN IRON TABLET}

Gérard Babatasi, MD, ${ }^{a}$ Massimo Massetti, MD, ${ }^{\mathrm{a}}$ Françoise Galateau, MD, ${ }^{\mathrm{b}}$ Brigitte Mosquet, MD, ${ }^{\mathrm{b}}$ André Khayat, MD, ${ }^{a}$ and Claude Evrard, MD, ${ }^{a}$ Caen, France

The late occurrence of bronchial stenosis after inhalation of iron tablets has been described. Inhalation of iron tablets causes rare tissue necrosis caused by local release of cytotoxic oxidant radicals, which results in bronchial perforation. We observed a dramatic early complication in the form of acute bronchial necrosis in two patients, who required pulmonary resection. In this report we review the literature concerning this topic. We stress that early diagnosis and management (bronchoscopy) are mandatory to avoid caustic bronchial erosion.

Case reports. CASE 1. A 59-year-old woman consulted a physician 4 days after inhalation of a ferrous sulphate tablet. She was taking Tardyferon tablets ( 1 brownish pink-coated tablet 4 times a day; ferrous sulphate 256.26

From the Thoracic and Cardiovascular Surgery Department ${ }^{\mathrm{a}}$ and the Department of Pathology, ${ }^{\mathrm{b}}$ University Hospital Caen-côte de Nacre, Caen, France.

Received for publication Feb. 26, 1996; accepted for publication April 1, 1996.

Address for reprints: G. Babatasi, MD, Thoracic and Cardiovascular Surgery Department, University Hospital Caen-côte de Nacre, 14033-Caen, France.

J Thorac Cardiovasc Surg 1996;112:1397-9

Copyright (C) 1996 by Mosby-Year Book, Inc.

$0022-5223 / 96 \$ 5.00+0 \quad \mathbf{1 2 / 5 4 / 7 3 9 1 8}$ $\mathrm{mg}$, mucoprotease $80 \mathrm{mg}$, and ascorbic acid $30 \mathrm{mg}$; Laboratoires Robapharm, Les Ulis, France) for mild anemia. A fiberoptic bronchoscopic examination revealed, after extraction of the tablet, a necrotic and inflammatory process of the mucosa of the right distal bronchus. Four days later, a second bronchoscopic examination showed inflammatory lesions of the right intermediate bronchus with patchy necrosis of the mucosa.

Nine days after the first consultation, the patient reported two episodes of hemoptysis and was transferred to our thoracic unit. Chest examination showed wheezing and decreased air entry. Chest roentgenography revealed collapse of the right lower lobe. Another episode of hemoptysis caused hypovolemic shock and necessitated bronchoscopy, which showed a polypoid mass and ulceration in the bronchial posterior zone. Five hours later, cardiac arrest occurred as a result of massive hemoptysis and an emergency thoracotomy was required. The right lung was entirely filled with blood and despite clamping of the pulmonary artery and pneumonectomy, the patient died. Massive necrosis with $1.5 \mathrm{~cm}$ long ulceration of the right intermediate bronchus and of the walls of both the pulmonary artery and the right upper vein were observed.

CASE 2. A 54-year-old man with a history of neonatal hypoxia and spastic paraplegia as a sequela was admitted to the emergency department because of vigorous coughing that produced a cupful of blood. The patient had a hiatal 